\title{
REGULAÇÃO DA PROPAGANDA ELEITORAL ANTECIPADA: A POSIÇÃO DO TSE QUANTO AO USO DE OUTDOOR NO RESPE № 0600227-31
}

Raísa Schaeffer ${ }^{1}$

Resumo: Este artigo analisa a posição firmada pelo Tribunal Superior Eleitoral no REspe ${ }^{0}$ 0600227-31.2018.6.17.0000, no sentido de serem extensíveis, ao período de pré-campanha, as vedações previstas para o período regular de campanha eleitoral, especialmente quanto ao uso de meios de propaganda proibidos. No caso, foi considerada ilícita e puní- vel com multa a divulgação da imagem e de características pessoais de pré-candidato em outdoors, meio de propaganda de uso expressamente vedado pela Lei Geral das Eleições durante o período de campanha.

Palavras-chave: Propaganda Eleitoral. Pré-campanha. Outdoor.

${ }^{1}$ Técnica Judiciária lotada na 94a Zona Eleitoral de Chapecó. Graduada em Direito. 
ELEIÇÕES 2018. RECURSO ESPECIAL ELEITORAL. ATOS DE PRÉ-CAMPANHA. DIVULGAÇÃO DE MENSAGEM DE APOIO A CANDIDATO. AUSÊNCIA DE PEDIDO EXPLÍCITO DE VOTO. UTILIZAÇÃO DE OUTDOORS MEIO INIDÔNEO. INTERPRETAÇÃ̃O LÓGICA DO SISTEMA ELEITORAL. APLICABILIDADE DAS RESTRIÇÕES IMPOSTAS À PROPAGANDA ELEITORAL AOS ATOS DE PRÉ-CAMPANHA. CIRCUNSTÂNCIAS FÁTICAS QUE APONTAM PARA A CIÊNCIA DO CANDIDATO SOBRE AS PROPAGANDAS. RECURSO PROVIDO.

1. A realização de propaganda, quando desacompanhada de pedido explícito e direto de votos, não enseja irregularidade per se.

2. A interpretação do sistema de propaganda eleitoral aponta ser incompatível a realização de atos de pré-campanha que extrapolem os limites de forma e meio impostos aos atos de campanha eleitoral, sob pena de se permitir desequilíbrio entre os competidores em razão do início precoce da campanha ou em virtude de majorada exposição em razão do uso desmedido de meios de comunicação vedados no período crítico.

3. A despeito da licitude da exaltação de qualidades próprias para o exercício de mandato ou a divulgação de plataformas de campanha ou planos de governo, resta caracterizado o ilícito eleitoral quando o veículo de manifestação se dá pela utilização de formas proscritas durante o período oficial de propaganda

4. As circunstâncias fáticas, do caso ora examinado, de maciço uso de outdoors em diversos Municípios e de expressa menção ao nome do candidato permitem concluir a sua ciência dos atos de pré-campanha, conforme exigência do art. $36, \S 3^{\circ}$ da Lei das Eleições.

5. A realização de atos de pré-campanha por meio de outdoors importa em ofensa ao art. 39, § $8^{\circ}$ da Lei n⿳ $9.504 / 97$ e desafia a imposição da multa, independentemente da existência de pedido explícito de voto.

6. Recurso especial eleitoral provido.

(Recurso Especial Eleitoral nº0600227-31.2018.6.17.0000, Acórdão, Relator Min. Edson Fachin, Publicação: DJE - Diário de justiça eletrônico, Número 123, Data 01/07/2019, Página 214)

O julgamento desse Recurso Especial Eleitoral analisa essencialmente se as vedações aplicadas à propaganda eleitoral no período legal de campanha podem ser estendidas também ao período de pré-campanha. Analisa-se o caso de um Defensor Público do Estado de Pernambuco que, nos meses anteriores ao início da campanha eleitoral, teve sua imagem di- 
vulgada em 23 outdoors, ao lado dos dizeres: "O defensor do povo! Seus amigos se orgulham por sua luta contra os invisíveis".

Inicialmente, discute-se o enquadramento da manifestação descrita como propaganda eleitoral. Superado isso, e tendo em vista a proibição do uso de outdoors durante a campanha eleitoral, analisa-se a legitimidade ou não da extensão dessa proibição também ao período de pré-campanha.

A liberdade de expressão e de comunicação são valores caros à democracia, previstos inclusive na Constituição Federal. Esses princípios regem, também, a propaganda política, na medida em que a livre circulação de ideias e a ampla divulgação dos ideais, projetos e posturas de um candidato fortalecem uma escolha bem pensada por parte do eleitor.

No entanto, essas liberdades não são plenas, e encontram limitação nos princípios da veracidade e da isonomia, que igualmente norteiam a dinâmica da propaganda política (GOMES, 2016, p. 472). Portanto, na campanha eleitoral, não se pode dizer tudo quanto se queira, pois o que é dito deve condizer com a realidade; por outro lado, o meio pelo qual a propaganda eleitoral será divulgada deve, em princípio, ater-se a modalidades que garantam aos demais concorrentes igual oportunidade de alcance a eleitores.

É na ponderação entre essas liberdades e esses deveres que se localiza a discussão proposta. $\mathrm{O}$ tema da propaganda eleitoral é vastamente regulado em lei, a fim de bem delimitar esses direitos e deveres. Em casos limítrofes, a jurisprudência é chamada a analisar e elucidar normas conflitantes ou omissões legislativas. Assim, será analisada a dimensão legal da propaganda política antecipada, e, por fim, será trazido o posicionamento predominante do TSE quanto ao caso sob análise.

Por considerável período, a propaganda eleitoral, quanto à época de sua veiculação, dividiu-se em propaganda eleitoral regular e propaganda eleitoral antecipada, esta última vedada de forma absoluta na redação original da Lei no 9.504/1997. Assim, aqueles atos que objetivavam de alguma forma promover um candidato, caso ocorressem dentro do período de campanha eleitoral, que se iniciava no dia 5 de julho do ano da eleição, eram em princípio legítimos, observadas outras restrições. Por outro lado, todo e qualquer ato que ocorresse antes da data limite era tido como ilícito.

A situação mudou quando, em 2009 , foi sancionada a Lei ${ }^{\circ}$ 12.034, que acrescentou à Lei $n^{\circ} 9.504 / 1997$ o art. 36-A. O artigo previa que "não seria considerada propaganda eleitoral antecipada" a participação 
de pré-candidatos em entrevistas, programas e debates na mídia e na internet, desde que não houvesse pedido de votos. Da mesma forma, não estaria sujeita à multa a realização de encontros em ambientes fechados com viés intrapartidário, para tratar da organização do processo eleitoral, bem como a realização de prévias partidárias e sua respectiva divulgação. Por fim, não poderia ser entendida como ilícita a divulgação de atos de parlamentares, desde que não se mencionasse futura candidatura ou se pedisse votos.

Com isso, criou-se a improvável figura da propaganda eleitoral antecipada que, por imposição legal, "não seria considerada propaganda eleitoral antecipada". Como se verá no desenvolvimento dos argumentos jurídicos utilizados na decisão analisada, tratou-se de impropriedade legislativa, pois o que a lei objetivou, primordialmente, foi tornar lícitas algumas modalidades de propaganda eleitoral antecipada que eram antes consideradas ilícitas - e não determinar que essas modalidades não mais seriam consideradas propaganda eleitoral antecipada, a contrário do que se fez parecer. Uma melhor forma de colocar essa mudança seria através da divisão da propaganda eleitoral antecipada entre regular e irregular. As hipóteses elencadas no art. 36-A são propagandas antecipadas regulares, desde que não incluam pedido expresso de voto, ao passo que quaisquer outros atos de propaganda antecipadas seriam ilícitas, sujeitas à multa.

A Lei no 12.891/2013 ampliou o rol de atos que não seriam considerados propaganda eleitoral antecipada e incluiu permissão expressa de que esses atos poderiam ser divulgados nos meios de comunicação social, inclusive pela internet. A justificativa para a alteração era tornar as campanhas mais baratas, por meio da permissão expressa de realização de campanha eleitoral antecipada na internet, que é de alto alcance e baixo custo.

Em 2015, foi promulgada a Lei $n^{\circ}-13.165$, configuração vigente até hoje. Ao passo em que o período de campanha estreitou-se, tendo seu início postergado para o dia 15 de agosto do ano eleitoral, alargaram-se ainda mais as possibilidades do que pode se chamar de propaganda eleitoral antecipada regular: passou-se a admitir a menção à pretensa candidatura, a exaltação de qualidades pessoais dos pré-candidatos, a divulgação de posicionamento pessoal sobre questões políticas e a realização de reuniões para divulgar ideias e propostas, desde que os custos fossem cobertos pelo próprio partido. Foi ainda adicionado ao art. 36-A o $\S 2^{\circ}$, que dispõe que, nas hipóteses de campanha antecipada regular, são permitidos o pedido de apoio político e a divulgação da pré-candidatura, das ações políticas desenvolvidas e das que se pretende desenvolver. 
Manteve-se a proibição ao pedido explícito de voto, valendo em relação a todas as hipóteses autorizadas de propaganda eleitoral antecipada. O Min. Edson Fachin afirma, no relatório do REspe analisado, que, afora a essa proibição de pedido explícito de votos, já não mais se distingue sensivelmente a propaganda eleitoral antecipada da propaganda eleitoral realizada no período legal.

Com tantas exceções previstas em lei, fato é que resultou abrandada a proibição da propaganda eleitoral extemporânea. Assim, cabe à jurisprudência analisar, nos casos concretos, eventuais ocorrências de abuso, conferindo aos fatos da vida real uma interpretação que se adeque a todo o ordenamento jurídico referente a eleições (GOMES, 2016, p. 494).

Além da distinção quanto à época de veiculação, a propaganda eleitoral pode ser dividida entre permitida e vedada, a depender da forma como é divulgada. O uso de outdoors é um meio de propaganda eleitoral que hoje é expressamente vedado pela lei. A proibição encontra razão em seu grande alcance e alto custo, o que pode desorganizar a igualdade de condições de alcance de eleitores a que a lei eleitoral objetiva.

Até 2006, o uso de outdoors para propaganda eleitoral era permitido e regulamentado no art. 42 da Lei no 9.504/1997. Em 2006, com a Lei no 11.300, revogou-se o referido artigo, retirando-se de forma absoluta a possibilidade do uso de outdoors, com a finalidade de reduzir os gastos eleitorais. Restringiu-se, assim, eventual margem de influência do poder econômico nas eleições. Atualmente essa proibição é prevista no art. $39, \S 8^{\circ}$, da Lei $n^{\circ}$ 9.504/1997.

Feito esse breve apanhado histórico da legislação, passa-se aos fundamentos jurídicos utilizados na decisão. Para fins de aplicação da lei eleitoral, o TSE consolidou a seguinte definição para "propaganda eleitoral":

[ato] que leva ao conhecimento geral, ainda que de forma dissimulada, a candidatura, mesmo que apenas postulada, a ação política que se pretende desenvolver ou razões que induzam a concluir que o beneficiário é o mais apto ao exercício de função pública. Sem tais características, poderá haver mera promoção pessoal - apta, em determinadas circunstâncias, a configurar abuso de poder econômico mas não propaganda eleitoral. (Recurso Especial Eleitoral no $161-83$, Relator Ministro Eduardo Alckmin, DJ de 31.3.2000, p. 126) 
Como já afirmado, a ampliação da possibilidade de adiantar a discussão eleitoral trazida a partir da inclusão do art. 36-A - já que muitos atos caracterizados como propaganda eleitoral agora podem ser realizados desde antes do início do período de campanha - implica na construção de limites de alguma outra forma, especialmente a fim de garantir a observância ao princípio da isonomia.

Para tanto, o Ministro Relator desenvolve algumas regras para o período de pré-campanha, através da técnica da interpretação sistemática. Ainda que o art. 36-A não traga nenhuma regra expressa quanto à observância das vedações relativas à propaganda eleitoral do período de campanha propriamente dito, voltando-se para a Lei das Eleições como um todo, verifica-se a preocupação do legislador com a igualdade na disputa pela preferência do eleitor.

Dessa forma, caso no período de pré-campanha fossem toleradas as proibições relativas ao período eleitoral, a campanha eleitoral já seria iniciada num contexto de desequilíbrio entre os concorrentes. Essa disparidade poderia ser originada a partir do uso desigual dos meios de veiculação de propaganda, a exemplo do outdoor, que é expressamente vedado no período crítico de campanha.

O Relator retoma, então, um julgado anterior do TSE, o AgR-AI no 9-24/SP, de junho de 2018, no qual foram fixados critérios para identificar, na Eleição de 2018, se os limites legais para a propaganda do período pré-eleitoral estavam sendo observados ou não (Agravo de Instrumento $\mathrm{n}^{\mathrm{0}}$ 924, Acórdão, Relator Min. Tarcísio Vieira De Carvalho Neto, Publicação: DJE - Diário de justiça eletrônico, Data 22/08/2018). Eram eles:

- O pedido explícito de votos torna a propaganda antecipada irregular, haja vista sua expressa proibição;

- Atos de propaganda não eleitorais, indiferentes à disputa eleitoral, ficam de fora da jurisdição da Justiça Eleitoral;

- O uso de elementos típicos de propaganda não enseja necessariamente irregularidade; e

- A opção pela realização de pré-campanha, nas hipóteses autorizadas pelo art. 36-A, acarreta a necessidade de se observar as seguintes exigências: impossibilidade de utilização de formas proscritas durante o período oficial de campanha e respeito ao alcance das possibilidades do pré-candidato médio. 
Assim, reposicionando esses critérios, teríamos os seguintes passos para verificar se a propaganda eleitoral adiantada é regular ou não: primeiro, averiguar se a propaganda tem finalidade eleitoral, a fim de constatar a possibilidade de a Justiça Eleitoral exercer seu controle; depois, analisar a existência de pedido explícito de votos, o que torna o ato irregular; por fim, averiguar se $\mathrm{o}$ ato de propaganda não incorreu em algumas das proibições do período oficial de campanha.

No caso sob julgamento, o Defensor Público de Pernambuco que teve sua imagem divulgada em 23 outdoors era sabidamente pré-candidato, pois havia realizado consultas no TRE e se filiado a Partido Político em ato com a presença do Governador do Estado. Ademais, noticiários locais já haviam informado que o cidadão iria disputar cargo de deputado estadual. Assim, à época da veiculação do outdoor, estava clara sua conexão com o período eleitoral.

Especialmente se considerados os dizeres que acompanhavam a imagem e o nome do Defensor, que o colocavam como "o defensor do povo" graças a sua "luta pelos invisíveis", vê-se a intenção da referida propaganda de influenciar os eleitores locais, mediante a exaltação de características do pré-candidato em período próximo ao eleitoral, a ser iniciado em aproximadamente 4 meses.

Os outdoors foram, ainda, confeccionados em larga escala, sendo 23 espalhados em 3 municípios. O potencial de divulgação de 23 outdoors supera o argumento da defesa do candidato de que teriam sido elaborados por amigos, com a finalidade única de homenagear o Defensor por seu trabalho realizado enquanto servidor público.

Elucida-se que, no caso, o conteúdo da propaganda em si não incorre em nenhuma vedação relativa à propaganda eleitoral extemporânea. Isso porque o art. 36-A deixa claro ser lícito o ato de propaganda antecipada que leve a conhecimento e exalte características pessoais dos pré-candidatos. Ademais, não houve pedido explícito de votos, o que tornaria a propaganda irregular. A discussão centra-se, então, no meio utilizado para sua veiculação: os outdoors.

Assim, é considerada a orientação anterior do TSE para a Eleição de 2018, de que é ilícito na pré-campanha o uso de veículo de manifestação de propaganda eleitoral vedado no período de campanha oficial. O Pleno, então, firma entendimento no sentido de ser incompatível com uma interpretação integral do sistema eleitoral a realização de atos de pré-campanha que não observem os limites impostos à propaganda eleitoral do período oficial. 
O prejuízo, caso não se entendesse nesse sentido, seria uma situa- ção de concorrência assimétrica entre os candidatos, em razão de uma dis- puta iniciada de forma prematura e sem a observância de regras essenciais ao andamento justo da campanha eleitoral.

Vale dizer que, na hipótese, a Justiça Eleitoral não está tolhendo odebate de ideias ou reprimindo a divulgação de informações sobre pré-can- didatos, pois existem outros meios de realizar essa apresentação. A Justiça Eleitoral intervém porque a divulgação de nome e imagem de pré-candi-dato em 23 outdoors não está ao alcance do pré-candidato médio. Trata-se de propaganda de alto custo, que pode dar margem ao abuso de poder econômico na corrida eleitoral. A título ilustrativo expõe-se que se a mesmamensagem tivesse sido divulgada nas redes sociais, seria lícita.

Além disso, o Min. Og Fernandes aponta em seu voto que os gastos realizados durante o período oficial de campanha devem ser rigo-rosamente declarados, mediante prestação de contas que deve comprovarinclusive a origem lícita dos recursos. Não faria sentido imprimir tamanha rigidez ao período eleitoral regular e, por outro lado, permitir a produção depropaganda de maneira ilimitada durante a pré-campanha.

Por todos fundamentos expostos, nesse julgado o Plenário do TSE firma o entendimento de que as vedações previstas na Lei de Elei- ções para o período oficial de campanha são extensíveis às modalidades de propaganda eleitoral antecipada autorizadas pelo art. 36-A. É uma posição inédita assumida pelo Tribunal, que, anteriormente, julgava que a propagan-da antecipada seria irregular apenas na hipótese de haver o pedido explícitode votos. Trata-se de um grande passo em direção à isonomia e uma boasinalização acerca da importância de se perquirir uma corrida eleitoral maisjusta, desde seu início e até mesmo antes do período oficial.

Assim, por maioria, os Ministros entendem caracterizado o ilícito eleitoral. Por haver uso de meio inidôneo para veiculação de propagan- da eleitoral antecipada, é configurada a infração ao art. 39, § $8^{\circ}$,-da Lei ${ }^{\circ} 9.504 / 1997$, com a imposição de multa de $\mathrm{R} \$ 5.000,00$ ao pré-candidato.

\section{Referências}

GOMES, José Jairo. Direito Eleitoral.12. ed. - São Paulo: Atlas, 2016. 